\title{
Fundamentos da Prática Docente: Por uma Pedagogia Ativa
}

Cilene Ribeiro de Sá Leite Chakur*

\section{RESUMO}

O artigo pretende mostrar como a questão dos fundamentos da prática docente é prioritária numa discussão sobre as falhas, incoerências e insatisfações do professor em sua tarefa diária, constituindo-se em ponto de partida para uma análise do ensino atual. São apontadas confusões e ambigüidades da prática docente, bem como a permanência de características da pedagogia tradicional, com suas suposições e implicações para o desenvolvimento e a aprendizagem do aluno. Ao final, são apresentados princípios psicológicos e epistemológicos da teoria piagetiana passíveis de fundamentar uma pedagogia ativa, e sugestões para sua efetivação na prática, visando atender à finalidade educacional de "desenvolvimento das potencialidades do educando" em novas bases.

\section{INTRODUÇÃO}

As preocupações do professor com o seu trabalho, cm sala de aula, são de várias ordens e nem sempre suficientemente claras e bem definidas. São exemplos de suas atribuições diárias: chegar ao final do programa dentro do prazo previsto; suprir as dificuldades de aprendizagem dos alunos; escolher recursos didáticos adequados à apresentação do conteúclo; claborar tipos de atividades e formas de avaliação dos alunos; e, principalmente entre professores recém formados, encontrar estratégias apropriadas ao desenvolvimento do conteúdo e à consecução dos objetivos propostos.

Entre os objetivos visados pelo professor, encontra-se o "desenvolvimento das potencialidades" do aluno e de sua capacidade de pensar, objetivo este também presente nas propostas da legislação para o ensino de 1o. e 2o. graus. Em geral, os objetivos são apenas propagados ou colocados formalınente e não há garantias de que, ao término de um programa, sua consecução esteja bem encaminhada.

Quanto às estratégias e recursos didáticos, a insatisfação parece ser geral, mas em grande parte inconsciente. Ao professor, não fica claro se os caminhos escolhidos são os melhores na persecução dos objetivos e, ao mesımo tcmpo, os mais adequados à apresentação dos conteúdos do programa. Afora

* Protessora Assistente-doutor do Departamento de Psicologia da Educação da Faculdade de Ciências e Letras - Unesp/Campus de Araraquara 
as queixas pela falta de recursos materiais da escola, que se acompanham da falsa tranqüilidade de consciência do professor, sem afastar certo sentimento de culpa resultante da acomodação às 'condições dadas.

É comum, aliás, que os fracassos sentidos no âmbito técnico-pedagógico sejam interpretados de modo inconsistente, recorrendo-se a fatores circunstanciais: se a classe demonstra dificuldade específica, a falha está no ensino deficiente nas séries anteriores e, em última instância, na falta de preparo técnico do professor; se o fracasso é generalizado, explica-se pelas condições existenciais do aluno ou por deficiências estruturais da escola (nível sócio-econômico e estrutura familiar, falta de recursos auxiliares em casa e na escola, classes numerosas, etc.); se a dificuldade é sentida por poucos alunos, o fracasso é atribuído a eles próprios, sendo questão de "pouca inteligência" ou "baixo QI" (Cf. BARRETO, 1981).

Mas o maior problema da aluação docente, ao nosso ver, está em sua fundamentação pedagógico-epistemológica.

Apresentaremos, a seguir, certas confusões e ambigüidades presentes na fundaınentação do trabalho docente, apontando a distância entre o real $\mathrm{e}$ o desejável, responsável pela permanência do ensino tradicional em nossas escolas. Traçaremos algumas características do atual ensino brasileiro de 10. e 2o. graus, levantando suas suposições implícitas e implicações para a aprendizagem e o desenvolvimento do aluno. $E$, finalmente, abordaremos alguns princípios psicológicos e epistemológicos que podem fundamentar uma pedagogia ativa sob a perspectiva piagetiana, com sugestões de como tornálos efetivos na prática pedagógica que pretenda "desenvolver as potencialidades" do aprendiz.

\section{Pressupostos da pedAgogia tRADICIONAL E SUAS}

\section{REPERCUSSÕES NA PRÁTICA DOCENTE}

A começar pelos valores e representações idealizadas, o preparo pedagógico que o professor recebe, como lembra BARRETO (1981, p. 302), "foi todo concebido em função de um aluno ideal, limpo, sadio, disciplinado e inteligente (...) afora a concepção idealizada do magistério como sacerdócio". No mais das vezes, o futuro professor sai também convencido de que seus valores e sua visão de mundo são os mclhores e os únicos legítimos. E é neste senticlo que procurará convencer os alunos da superioridade dos padrões de condula que transmite sobre aqueles que eles trazem do ambiente familiar ou social, crigindo tais padrões como modelos a serem imitados.

Tais concepções e atiludes críticas do professor, bem como o trabalho efetivo em sala de aula, fundamentam-se em princípios que vêm orientando a prática pedagógica desde o século XVIII (ou talvez antes), modificados apenas superficialmente em função do avanço técnico e da ideologia contemporânea.

As orientações, aliás, se polarizam entre o respeito e atenção às fa- 
culdades espontâneas do homem, da visão humanista, e a importância dada à sua transformação para que se adaptem à sociedade, própria da visão tecnocrática. De um lado, valoriza-se a consciência enquanto capacidade comum a todos os homens e, por isso mesmo, determinante dos idcais de igualdade, liberdade e responsabilidade, dissimulando-se as diferenças $\mathrm{cm}$ função do fator maturacional e do esforço; de outro lado, o papel da consciência é diluído frente aos ideais de competência e eficiência, sustentando-se as diferenças no peso conferido ao fator ambiental. No primeiro caso, o professor teria por tarefa despertar a consciência latente do aluno, detectando seu potencial inato e favorecendo sua expressão; no segundo, seria seu papel suprimir a situação de ignorância, estimulando no aluno o desejo de saber e modelando suas condutas que, ao final, o levariam a competir com os melhores e a garantir sua posição na hierarquia social.

Na realidade de sala de aula, porém, essas duas orientações muitas vezes situam-se em planos distintos. No plano da concepção e do discurso, acredita-se que o indivíduo dispõe a priori de "scmentes do saber", potencialidades inatas cuja evolução segue uma ordem natural (como cm COMENIUS, ROUSSEAU e, mais modernamente, A. S. NEILL e C. ROGERS). É comum, por exemplo, o professor surpreender-se quando o aluno apresenta sinais de que não sabe determinada coisa, "tão clementar", entretanto.

Mas no plano da atuação efetiva, o que se nota é a sistcmálica de planejamento detalhado e organização mais ou menos rígida de siluações de ensino-aprendizagem, com o recurso a estímulos ambientais e reforços do comportamento em direção a objetivos extra-individuais e nada naturais. Neste caso, contraria-se o discurso correspondente, que concebe a razão humana como tabula rasa a ser equipada ou preenchida convenientemente (como em LOCKE, HERBART e tcóricos associacionistas e mecanicistas em geral).

Vemos, assim, que as ambigüidades presentes nas crencas co professor podem muito bem ser as responsávcis por suas insegurangas e pelas faIhas e dificuldades em sua aluação. A distância entre o real latuação efeliva) e o descjável (concepções e discursos) é também fruto de incoerências da própria legislação educacional e das propostas de implantação a nível estadual, como ilustram a Lei 5692/71 e documentos complementares.

Em cursos de atualização e treinamento, os professores são informados, por exemplo, que o ensino de 10. grau deve variar "em conteúdo e mélodos segundo as fases de desenvolvimento dos alunos" (LEI 5692/71, Art. 17); c que os conteúdos curriculares e o processo de ensino devem respeitar a seqüência "da maior para a menor amplitude do campo abrangido, constituindo atividades, áreas de estudo e disciplinas" (RESOLUÇ.ÃO CFE no. 8/ 71, Art. 40., parágrafo 10.).

O modelo psicológico seguido para a definição de fases de desenvolvimento e de categorias curriculares é claramente o piageliano (veja-se, por excmplo, o PARECER CFE no. 853/71). Mas os documentos, relatórios c obras explicativas pecam, muitas vezes, pela utilização de termos e expressões com sentidos diferentes dos que lhes dá PIACET, fornecendo, inclusive, visão 
deformada das fases de desenvolvimento propostas por este autor ${ }^{(1)}$. Exemplificam esses erros de interpretação, a inclusão de "hábitos" e "comportamentos estereotipados" entre as características do período das operações concretas; a confusão entre os termos "intuitivo" e "concreto"; a identificação de "esquemas lógicos" com a lógica do adulto; e, principalmente, a proposta de Atividades (com sentido dos mais ambíguos) como a categoria curricular que deve corresponder ao período das operações concretas. Como se sabe, para PIAGET, atividade não se identifica com uma fase particular, sendo todo conhecimento, em qualquer nivel, uma ação transformadora.

Tendo em vista as confusões e ambigüidades que tornam incompreensíveis as propostas legais, os professores optam por continuar com as suas próprias incocrências e seguir na prálica preceitos amplamente utilizados e aceitos da pedagogia tradicional. Veremos, a seguir, como isto ocorre.

\section{A PERMANÊNCIA DA PEDAGOGIA TRADICIONAL:}

\section{SUPOSIÇŌES E IMPLICAÇŌES}

Certos traços da pedagogia tradicional que se perpetuam na atuação docente são mais freqüentes que outros mas, cm scu todo, compõem um bloco de caracteres unidos por suposições firmemente entrelaçadas e advindas, em geral, da visão "sensual-empirista" de que fala AEBLI (1978). Apresentaremos os traços mais comuns e/ ou relevantes desta visão, tentando, em cada caso, desvendar as suposições implícitas que thes dão sentido.

\section{1. ẾNFASE No Símbolo e na formalizaçāo}

PIAGET cosluma referir-se ao uso de símbolos e signos como manifestação da função semiótica, presente na criança no início do período Operacional Concrelo. No estádio Pré-operatório, como bem diz o nome, a criança ainda não (lispõe de operações, ou seja, não é capaz de execular mentalmente ações reversíveis (utilizar a inversão e/ou a reciprocidade), embora consiga agir simbolicamente (representar uma coisa por meio de outra).

Enquanto o símbolo é de caráter molivado, de criação individual, o signo (comum ou lécnico) é arbitrário e convencional. Em ambos, o significante diferencia-se do significado, inversamente ao que acontece com o índice - em que o significado é parte ou aspecto do objeto, ou scu resultado causal - c com o sinal - que funciona do mesmo modo que o estímulo original, como no esquema S-R de cóndicionamento (CF. PINGET, 1975).

Tomaremos aqui o termo símbolo na acepção acima, deixando formalização para o caso da utilização de signos arbitrários.

A ênfase do professor sobre o emprego de símbolos e da formalização

(1) Ci. CHAGAS, 1978; Săo Paulo, 1973; c São Paulo, 1975. 
parece apoiar-se na suposição de que a atividade de representar por símbolos ou signos traduz, necessariamente, uma operação subjacente; e reciprocamente, se o aprendiz não sabe simbolizar ou formalizar, é sinal de que não dispõe da operação em jogo. Outra suposição implícita é a de que a atividade pura e simples de representar aumenta os conhecimentos.

Contrariamente, a utilização de símbolos ou signos muitas vezes indica apenas a presença do que AEBLI (1978) chama de "hábito relativo ao manejo de símbolos", sem qualquer operação subjacente: se 0 aprendiz segue pistas para chegar à solução desejada, suas representações se fariam de forma automática, prescindindo da compreensão.

Os comentários de GUINSBURG (1978, p. 168-169) são também esclarecedores: "a atitude do aluno diante de determinados signos, como ' $+{ }^{\prime},{ }^{\prime}-{ }^{\prime}, ' x^{\prime}, '(x 2)^{\prime},{ }^{\prime}()^{\prime}$ ', que the são familiares, que ele já 'experienciou' de algum modo no curso do 10 . Grau, é a mesma que ele teria em face de um signo que indicasse 'mão única' em uma via pública (...) para o aluno em tcla, a relação entre o significante do signo, isto é, a relação entre as propriedades ou qualidades do signo, e o seu significado ou sentido, é uma relação quase inteiramente indicial, proveniente de vivências, experimentações, hábilos, etc.".

$\mathrm{Na}$ verdade, símbolo e signo não contêm o significado em si, nem o conhecimento se aperfeiçoa apenas com o seu emprego. A significação de um símbolo ou de um signo só pode ser reconhecida se o sujeito dispuser do esquema de assimilação adequado. É este esquema, aliás, que confere significado à representação.

Assim sendo, não saber lidar com símbolos ou com a formalização não implica, necessariamente, ausência de operações. Mas se a representação, qualquer que seja, revela compreensão antes que hábito, provavelmente o aprendiz já dispõe das operações que the dão sentido.

\section{A UTILIZAÇĀo DE DADOS SENSIVEIS E A IMPORTÂNCIA DA IMAGEM MENTAL}

O preceito básico a orientar a utilização de dados sensíveis, que pretende tornar o ensino mais "intuitivo", parece ser o de que "nada há na inteligência que não tenha estado, antes, nos sentidos" (W. REIN, apud AEBLI, 1978, p. 8).

Tentando adequar o ensino à "mentalidade concreta" do aprendiz, o professor lança mão de figuras, mapas, cartazes, objetos concretos, sólidos geométricos, etc., oferecendo-os à percepção e observação dos alunos. A suposição, aqui, é a de que o observável se imprime em imagem na mente, variando a impressão conforme o grau de sensibilidade ou receptividade do aprendiz. Acredita-se, em conseqüência, que as noções são derivadas de imagens mentais e, como tais, vêm do exterior.

O exemplo da utilização de carimbos com os contornos e limites de países e Estados, no ensino de Geografia, é bem ilustrativo: do mesmo modo 
que se copia a figura no papel, imprime-se também o seu sentido na mente do aprendiz. É comum, igualmente, solicitar-se a pintura ou recorte da figura, na esperança de que o aluno grave mais nitidamente a impressão.

Esquece-se, nessa prática, de que a reprodução do percebido ou observado depende do nível de organização cognitiva do aprendiz. Por mais frequiente que tenha sido a apresentação do objeto ou figura, o sujeito retém em imagem apenas aquilo que "sabe" ou compreende no momento. $O$ "processo de impressão" não é, pois, de natureza passiva e automática: há verdadeira reconstrução interior do observável. Como afirma PIAGET (1976 a, p. 46), - observável é aquilo "que o sujeito crê constatar e não simplesmente lo que] é constatável. É o mesmo que dizer que uma constatação nunca é independente dos instrumentos de registro (logo, de uma assimilação) de que dispõe o sujeito".

\section{Demonstração de açōes e operaçōes}

A apresentação de figuras e objetos pode requerer alguma demonstração pelo professor. É este, portanto, que se aplica em ações e operações que os alunos devem acompanhar, cada um por si.

A suposição aí implícita é a mesma mencionada atrás: idéias, noções e operações em geral vêm do exterior e a tarefa do aprendiz é "copiá-las" interiormente, por um processo de imitação. Assim, acompanhar a demonstração (prestar atenção) asseguraria automaticamente a aprendizagem do que foi apresentado.

Na verdade, o conteúdo demonstrado está sempre sujeito a deformações por parte do aluno e não há garantias de que a sua compreensão tenha o mesmo sentido daquele empregado pelo professor. Se não é o próprio aluno que realiza as ações, a compreensão pode ser parcial ou deformada e o que o sujeito retém do que foi demonstrado, para posterior aplicação, sempre depende, como mencionado, do que ele compreende naquele momento.

\section{Aula expositiva: Ênfase na linguagem Verbal}

A demonstração de ações e operações é prática que vem sempre associada à linguagem verbal, lípica do ensino expositivo. As implicações da ênfase em signos lingüísticos já foram comentadas, mas outras considerações são importantes.

Afirmamos que, quando a compreensão está ausente, a utilização de signos pelo aprendiz leva-o ao hábito automatizado - a seguir pistas, ao invés de raciocinar. A ênfase na linguagem verbal parece, então, apoiar-se na suposição de que a repetição mecânica do que expôs o professor é sinal de que o conteúdo foi aprendido. Assim sendo, o manejo da linguagem correta implicaria na aquisição tanto dos conceitos transmitidos como dos instrumentos necessários à própria assimilação.

Mas a linguagem verbal pode ser tomada pela criança de modo tão egocêntrico quanto qualquer símbolo individual. FURTH (1972, p. 110-111), 
por exemplo, açedita que "há dano real quando se impõem padrões lingüísticos no cömeço da educação formal, quando o comportamento lingüístico é utilizado como critério de capacidade intelectual numa idade em que a linguagem ainda está muito atrasada em relação à capacidade disponivel do pensamento operativo." A linguagem só se torna via adequada para expressar o pensamento após o estabelecimento das operações formais, na adolescência. Até então, qualquer incompreensão do verbalizado é compensada pela memorização ou outra conduta automatizada.

Quanto aos conceitos que se pretende transmitir com a linguagem, não provêm dela, 'e sim dos esquemas de assimilação do sujeito. São, pois, adquiridos tão espontaneamente quanto qualquer instrumento de assimilação.

\section{ConteÚdos dados PRONTOS E ESQUEMA ATOMISTICO}

\section{DE TRANSMISSĀO}

Na prática da demonstração e no ensino expositivo, o contcúdo geralmente é tratado de modo compartimentado. As noções são cuidadosamente scparadas, de modo a não "fazer confusão na cabeça do aluno". É comum em gramática, por exemplo, tratar os elementos da oração (sujeito, predicado, etc.) isoladamente, para que a função de cada elemento fique bem definida; ou em Matemática, ensinar as operações (adição, subtração, etc.) seguindo uma ordem fixa e abordando uma de cada vez.

A suposição, nesse caso, é a de que as idéias dadas cm conjunto, ao mesino tempo, poderiam interferir no processọ de sua "gravação": as impressões poderiam "apagar" umas às outras se geradas conjuntamente.

Inversamente, o esquema atomístico de separação de idéias c noções pode criar dificuldades para que o aluno estabeleça relações e possa recordar o conteúdo fora do contexto original que the dava sentido, sendo pouco provável sua aplicação em outras situações. Resta ao aluno, portanto, novamente apelar para a memorização.

Além de atomizado, o conteúdo geralmente é dado "pronto", de modo a atender os limites de duração do programa e a chegar aos alunos de forma já sistematizada, organizada. Supõe-se, ao que parece, que o conteúdo previamente organizado torna mais rápida a aprendizagem e facilita a tarefa docente. Fornecer já pronto o contcúdo evita, por um lado, que o aluno possa elaborá-lo e organizá-lo ao seu modo (fatalmente com incorreções) c, por outro, é forma segura de "equipar" o pensamento.

Contrariamente a essas suposições, sabemos que, qualquer que seja a idade do aprendiz, ele dispõe de estruturas mentais passíveis de organizar o contcúdo escolar de algum modo. Evidentemente, a forma de organização é difcrente conforme o nivel em que se situam essas estruturas. Mas apenas diferente, não certa ou errada no absoluto, se considerarmos que existe uma seqüência progressivamente mais avançada nas formas de organização de qualquer conteúdo, em função do desenvolvimento do aprendiz. 
Desse modo, se não é possível ao aprendiz organizar em dado nível os conteúdos transmitidos, resta-Ihe apenas devolvê-los de forma repetitiva e mecânica. $E$ a ausência de trabalho mental que isto implica freqüentemente gera o desinteresse, em grande parte responsável pela apatia e mau rendimento escolar.

\section{A RELAÇĀo PEDAGÓGICA: AUTORIDADE E DEPENDÊNCIA}

Todas as características levantadas atrás têm um espaço próprio: a autoridade docente como relação pedagógica e o vínculo da dependência como traço de união. É necessário, entretanto, diferenciar a autoridade decorrente do papel, ou outorgada pela hierarquia existente na instituição, daquela conquistada e assumida independentemente do papel ou da posição hierárquica, caracterizada pela ausência do impulso de controlar e dominar o outro. É a primeira, infelizmente, que predomina na instituição escolar.

O vínculo de dependência do aluno com relação ao professor é inerente à relação pedagógica autoritária. Segundo a descrição de BOHOSLAVSKY (1981), ele se funda nos seguintes pressupostos: "saber mais"; proteger o aluno para que não cometa erros; julgar o aluno e determinar a legitimidade dos seus interesses; definir a comunicação com o aluno, na qual são estabelecidos o contexto e a identidade dos participantes. Assim, "o professor é quem regula o tempo, o espaço e os papéis desta relação (...) quem institui um código e um repertório possível." (Op. Cit., p. 321).

Outras suposições podem ser levantadas. Por exemplo, a de que a relação autoritária e o vínculo de dependência são necessários porque o professor, enquanto adulto e sábio, fornece um modelo ideal de conduta que o aluno deve imitar se quiser ser um "adulto sábio". E que é preciso dobrar resiștências, impulsos e tendências indesejáveis desde a infância, pois "é de pequenino que se torce o pepino".

Sabemos, por outro lado, que a própria figura do professor já suscita na criança as reações desejadas: obediência, imitação crítica, passividade e conformismo. São reações naturais da fase de heteronomia anterior à adolescência, mas que podem ser (e são) reforçadas pela conduta autoritária do professor. Tal conduta pode, em conseqüência, prolongar as atitudes hetcrônomas da criança além do tempo necessário.

Além do mais, a relação autoritária, como muitas das características anteriores, mantém o aprendiz cm situação de isolamento, em que a única comunicação possível (ou permitida) se faz com o professor e, mesmo assim, com dificuldade. A siluação do "cada um por si" é ideal para o aparecimento do egocentrismo (intelectual ou afetivo) e das condutas individualistas.

Contrariamente, é a possibilidade de trocas de pontos de vista, na interação entre pares e com o professor, que torna mais fácil o acesso à compreensão, permite a superação do egocentrismo e é ocasião para o exercício da cooperação. 


\section{OS PRIMEIROS PASSOS DE UMA PEDAGOGIA ATIVA}

Os caminhos para se chegar a uma pedagogia ativa requerem a concciluação prévia do termo atividade, levantando-se as confusões a que dá lugar.

Ação é bastante confundida com manipulação motora, por exemplo. É difícil, para muitos, situar a ação no espaço interno ao sujeito, no plano do não manifesto e inobservável. Da perspectiva piagetiana, a ação motora ou melhor, sensorial-motora - predomina particularmente no período inicial de desenvolvimento da inteligência. Mas o pensamento da criança ou do adulto, enquanto ação mental (representação), é tão ativo quanto qualquer movimento manifesto.

Outra confusão que se faz é quando, aceita a ação no plano mental, contrapõc-se "atividade concreta" à "atividade abstrata". Mas uma ação mental pode aplicar-se a objetos já experienciados, familiares e, no caso, imaginados, permanecendo a ação tão presente e "concreta" quanto a que se situa no plano físico. É o que ocorre no período Operacional Concreto (estádios Pré-operatório e Operatório), em que a concreticidade é inerente ao pensamento. A criança é ainda incapaz de operar sobre o possível, fazendo-o apenas sobre objetos física ou mentalmente presentes que vivencia no momento.

Uma terceira confusão é a de que prevalece, na ação sobre objetos fisicamente presentes, a cognição figurativa sobre a operativa. PIAGET (1973 a, p. 71) define o aspecto figurativo do conhecimento como "tudo o que se dirige às configurações como tais, cm oposição às transformações (...) desempenha um papel preponderante (no sentido abusivamente preponderante e dependendo precisamente das transformações) no pensamento 'pré-operatório' da criança de 2 a 7 anos (...)". São instrumentos da cognição figurativa a percepção, a imitação e a imagem mental, que focalizam estados ou que tratam as transformações como sucessão de estados.

Quanto ao aspecto operativo, "é relativo às transformações e se dirige assim a tudo o que modifica o objeto, a partir da ação até às operações" (Op. Cit., p. 72). Abarca, portanto, as ações sensoriomotoras iniciais, as representações pré-operatórias e as operações propriamente ditas (concretas e formais).

Enquanto o aspecto figurativo tem sua fonte no mundo exterior, o operativo provém da atividade do sujeito.

Ao se recluzir a ação sobre objetos físicos a um processo figurativo, esquece-se, consequentemente, que o conhecimento não fornece uma cópia da realidade. Como afirma PIAGET (1976 b, p. 78), o conhecimento consiste essencialmente "de processos operativos que chegam a transformar o real, quer em ações quer em pensamentos, para perceber o mecanismo dessas transformações e assimilar, assim, os acontecimentos e os objelos a sistemas de operações (ou estruluras de transformações)". 
Esquece-se, também, que a experiência com objetos pode se dar de duas formas, sendo uma delas de natureza lógico-matemática, quando o sujeito abstrai propriedades da própria ação, antes que dos objetos; e que a segunda forma de experiência, de natureza física, ao permitir a descoberta de propriedades presentes nas coisas, não significa extrair dos objetos uma cópia meramente figurativa, mas necessita da ação transformadora do sujeito.

A atividade, portanto, é de natureza variada - perceptiva, motora, representativa, por exemplo; e obedece a certa gênese - da ação sensorialmotora à operação (concreta e formal). Qualquer proposta de uma pedagogia ativa deveria, pois, atender a essa ordem natural de sucessão da atividade, desenvolvendo-se o ensino segundo uma seqüência que parte da ação do aprendiz sobre objetos "ao vivo", à formalização, passando pelo intermediário da representação concreta.

Quanto à utilização de dados sensíveis no ensino, serviriam apenas como pontos de apoio da ação do aprendiz, por oposição à recepção passiva, valorizando-se, assim, a reconstrução ativa interior.

Ao invés das deınonstrações feitas pelo professor, há que se apelar para a ação e constatação do aluno, pois "ao se fazer experiências diante da criança em vez de fazê-las ela própria, perde-se todo o valor de informação e formador que apresenta a ação como tal." (PIAGET, 1976 b, p. 44).

A ênfase na linguagem verbal seria colocada como último passo da seqüência de ensino: a ação inicial sobre objetos físicos deveria, portanto, ser progressivamente substituída pela representação simbólica e, em seguida, pelos enunciados verbais, mesmo nas séries finais do 1o. grau, e no 20. grau.

Inversamente à prática dos conteúdos dados prontos e sua atomização, dever-se-ia considerar a livre organização feita pelo aluno, recorrendo-se à problematização que dá lugar à descoberta e à criação (ou reinvenção) e salientando-se as relações que favorecem a compreensão dos conteúdos $\mathrm{e}$ sua generalização.

A relação pedagógica, enfim, se fundaria no respeito mútuo e na cooperação: os trabalhos em equipe, a discussão conjunta e as trocas de pontos de vista dariam ensejo ao desenvolvimento da autonomia e ao desaparecimento gradual do individualismo e do egocentrismo.

Mas essas alterações na maneira comum de ensinar requerem fundamentos claros para que sejam sólidas. Apontaremos, a seguir, de modo mais organizado, cerlos princípios da tcoria piageliana, com algumas sugestões de como efelivá-los na prálica pedagógica diária.

1. O desenvolvimento intelectual é governado pelo processo de equilibração, ou seja, "pela compensação ativa oposta pelo sujeito às perturbações exteriores sofridas ou antecipadas." (PIAGET, 1973 b, p. 21). A 

estruturas intelectuais de nivel superior(2).

É papel do professor, neste caso, fornecer situações perturbadoras, que se constituam em desafios para o aluno, de modo não só a ativar suas estruturas cognitivas, mas também a desestabilizá-las, provocando o conflito cognitivo necessário à sua reorganização em novo patamar.

PIAGET (1976 a, p. 42) esclarece, entretanto, que "um mesmo dispositivo só é gerador de conflitos em certos níveis, para a estrutura considerada, quer dizer, ele não é perturbador por si mesmo e por assim dizer no absoluto, mas, ao contrário, é concebido como uma perturbação ou não o é, segundo os elementos já ou ainda não adquiridos da estrutura em formação."

\section{O desenvolvimento intelectual supõe níveis de organização carac-} terizados por estruturas cognitivas progressivamente mais elaboradas.

Numa situação escolar ideal - número pequeno de alunos por classe, clientela mais ou menos homogênea quanto à origeın social c a pré-requisitos acadêmicos e culturais em geral, além de sólida formação docente e assessoramento contínuo do professor em serviço -, faria parte da tarefa docente identificar a fase de desenvolvimento de cada aprendiz, a fím de ajuclálo na passagem à fase seguinte. Para tanto, o professor poderia recorrer ao método clínico piagetiano, de modo a verificar quais os significados dados pelo aluno ao conteúdo e à siluação de aprendizagem em geral. Logo, verificar quais as estruturas cognitivas presentes que dão sentido à siluação $\mathrm{c}$ permitem a assimilação não deformante.

Mesmo nessas condições utópicas, haveria certos inconvenientes, já salientados por COLL (1987), entre os quais ơ dispêndio de sim tempo relativamente longo com cada aluno individualmente e a exigência de pleno domínio do método de interrogatório piagetiano e de suas bases teóricas para a interpretação das condutas.

Em condições mais compativeis com a nossa realidacle, poderiamos contar, por exemplo, não tanto com a aplicação rigorosa do mélodo exploratório piagetiano, mas com certas atitudes do prof́cssor, a saber: respeito e atenção empática relativamente aos conteúdos que o aluno conseguiu assimilar até o momento e pesquisa constante de procedimentos didáticos que levem esse aluno a superar as dificuldades aluais.

Evidentemente, respeitar e perceber o que o aluno é capaz. cm dado momento não significa aceitar o fato passivamente. Assim como utilizar cm qualquer caso um procedimento que deu certo com alunos de uma séric particular, ou com determinados contcúdos, não caracteriza a alitude invesligadora. Quando se tem em vista o avanço da cognição, os desalios mencionados atrás são bastante úlcis ao diagnóstico do nível em que o aprendiz organiza os conteúdos, podendo lambém funcionar como recurso melodológico.

(2) PIAGET (1976 â) define perturbação como "algo que serve de obstáculo a uma assimilação" (p. 24), enquanto compensação refere-se a "uma ação de sentido contrário a determinado efcito e que tende, pois, a anulá-lo ou a neutralizá-lo" (p. 31). 
3. "Os conhecimentos derivam da ação" e o desenvolvimento espontâneo da inteligência caracteriza-se "pela constituição progressiva de sistemas de transformação", logo, pela operatividade (PIAGET, 1976 b, p. 37 e p. 42).

Tomando-se ação no sentido de atividade sobre objetos físicos, a ação do aluno seria o ponto de partida do ensino e da aprendizagem. O professor deveria utilizar, de início, objetos reais e, só depois, imagens e signos convencionais; partir da ação à formalização, aos poucos substituindo o "concreto" pelas operações dedutivas sobre enunciaclos verbais. Tudo isso tendo em vista que o conhecimento é sempre transformação e, como tal, um processo operativo que utiliza, na maioria das vezes, instrumentos figurativos a lítulo de meios.

Por essa razão, lambém seria tarefa do professor, numa pedagogia aliva, privilegiar o aspecto operativo da cognição, apelando para a compreensão, interpretação e criação do aluno, em lugar do hábito, da repetição e da reprodução, mais condizentes com a cognição figurativa. A ênfase estaria, portanto, na transformação significativa, antes que no observável, no descritivel e na configuração estática.

Com essas sugestões, não estamos pretendendo que o professor abra mão do seu papel, deixando o aluno agir livremente em sala de aula segundo sua vontade. COLL $(1987$, p. 188) igualmente já lembrou que "não basta que um aluno inicie uma atividade autodirigida para se ter a segurança que será também construtiva". Permanece fundamental a diferenciação entre processo de construção dos conhecimentos, cuja marcha é subınetida a uma gênese mais ou menos previsível, e processo educativo, intervenção de caráter intencional e imprevisível em seus resultados, cujo maior problema, diz COLL, está justamente em saber como interferir. Assim, mais que compreender e explicar como o aluno constrói os conhecimentos, é necessário ter em mente como se deve intervir para ajudá-lo nessa construção. E este é um problema que se coloca à pesquisa diária, à capacidade de discernimento e à criatividade do professor.

Por outro lado, não estamos descartando a importância do conhecimento figurativo, nem pretendendo que a aprendizagem de conteúdos escolares se reduza a aquisições de natureza lógico-matemática - proposta também severamente criticada por COLL (Op. Cit., p. 181), para quem "a competência operatória é um requisito necessário para a aprendizagem de determinados conteúdos, porém, em nenhum caso se confunde com esta."

Claro é que a natureza eminentemente social da educação escolar, de onde emergem as diretrizes para a seleção e organização dos conhecimentos considerados culturalmente valiosos, constitui-se na fonte que fundamenta a especificidade dos conteúdos transmitidos na escola. Entre outros exemplos, citaríamos a importância que tem para nós, brasileiros (se bem que não útil a todos), conseguir traçar mentalmente a imagem do mapa do nosso país, com seus Estados e frontciras vizinhas, e até mesmo memorizar os nomes das capitais; ou adquirir, via imitação, certos padrões lingüísticos que nos diferenciem de outras culturas; ou, ainda, aguçar nossa percepção 
auditiva e visual para o reconhecimento e apreciação de músicas e danças regionais. Num programa ortodoxamente piagetiano, certamente essas atividades não seriam contempladas, porque tipicamente geradas por instrumentos do conhecimento figurativo.

4. Um ambiente rico de estimulação favorece a ativação e o exercício de estruturas cognitivas total ou parcialmente elaboradas, bem como sua passagem a um nível superior de organização.

Trata-se de apresentar o conteúdo de modo tal que as idéias e noções possam ser relacionadas e, no caso das disciplinas especializadas, que possam ser compreendidas em suas conexões mútuas. Trata-se, também, de utilizar recursos didáticos que variem tanto em diversidade quanto em multiplicidade, provendo a situação de aprendizagem dos "alimentos" necessários ao funcionamento dos esquemas de assimilação.

Com isto, não há motivos para recear a não consecução do programa plancjado. A sugestão de mudança refere-se mais à forma de sua apresentação e desenvolvimento que ao programa propriamente dito. Um ou outro item pode ser retirado, substituído ou acrescentado, de modo a atender às limitações do aprendiz, se pretendemos ser coerentes com os fundamentos.

A "pobreza" da escola também não é motivo de desânimo, pois existem recursos materiais que nada têm de sofisticados e podem ser encontrados mesmo na natureza ou entre objetos, locais e situações de vida diária: espécimens vegetais e animais, amostras de rochas, campo aberto, ruas, estabelecimentos comerciais, de produção e de serviços, utensílios domésticos, palitos, botões, caixas, além do corpo próprio e/ou de outrem, são bons exemplos da riqueza pedagógica presente no cotidiano.

A utilização de recursos como esses, nas condições apontadas, favorece as atividades de descoberta e (re)invenção pelo aprendiz, sem limitá-lo à devolução rígida do conteúdo e sua aplicação apenas em contexto idêntico ao original.

5. A inteligência constitui-se na totalidade de estruturas cognitivas disponíveis pelo sujeito em dado momento do seu desenvolvimento. Como tal, não é mensurável quantitativamente.

$A$ inteligência não se refere a uma qualidade especial "que está presente nas 'quantidades' individualmente diferentes dentro de nós", nem é "algo a ser aprendido, assim como se aprendem fatos tais como o comprimento cm pés da maior ponte do mundo", como afirma FURTH (1974, p. 253). No domínio da inteligência operacional, a compreensão de um conteúdo ou a significação dada a um evento ou situação podem ser incompletas ou parciais, mas não "erradas", porque não quantificáveis.

Mesmo na aprendizagem de conteúdos acadêmicos específicos, sua avaliação deveria partir do ponto de vista daquilo que o aprendiz é capaz de fazer ou conceber em dado momento, e não do que está certo ou errado $\mathrm{cm}$ scu descmpenho, comparativamente ao padrão do adulto ou dos colegas mais adiantados da classe. A avaliação não seria, portanto, questão de "tudo 
ou nada", mas respeitaria o nivel de competência ${ }^{(3)}$ do aprendiz, que the permite emitir certas condutas em resposta às situações de ensino-aprendizagem apenas na medida em que é sensibilizado por estas.

Isto não significa que o professor deva se isentar de sua tarefa de "corrigir os erros". Analisar o tipo de erro em seu contexto e procurar saber por que foi cometido, bem como a prática de fornecer feedback, são procedimentos sumamente importantes para orientar não só o aluno, mas também o professor, nos passos seguintes. O que estamos sugerindo, enfim, é que seja o próprio aluno o termo de comparação, tomado individualmente e em vários momentos do processo ensino-aprendizagem.

\section{A sociabilidade evolui do individualismo e egocentrismo à coope-} ração e descentração; e da anomia à autonomia.

Cabe, então, ao professor, fomentar o trabalho cm equipe, a discussão e a troca de pontos de vista entre os alunos. Seria igualınente útil, a organização de situações propícias ao "ensino mútuo", em que os próprios alunos pudessem ensinar e corrigir uns aos outros, evitando-se assim, em grande parte, as reações já apontadas de dependência, obediência e imitação crílica, espontâneas e comuns entre os pequenos. Sob sua direção firme - distribuindo tarcfas, planęjando e organizando tempo e espaço, supervisionando o processo e (re)ordenando a composição dos grupos -, o professor poderia, inclusive, superar certas dificuldades decorrentes da numerosidade das classes, cuja heterogencidade tanto o angustia.

\section{CONCLUSÃO}

Nossa intenção neste trabalho não foi apresentar uma proposta educacional fechada, nem algum tipo de receituário para tornar o ensino mais "ativo". Ao invés, tentarnos questionar certos pressupostos do ensino tradicional e firmar nossa posição de que uma pedagogia ativa só se define como tal na medida em que seu perfil na prática se aproxima de scus fundamentos teóricos. E, vale salientar, levantamos apenas alguns desses fundamentos, que cobrem uma parte mínima da complexidade presente na realidade educacional, em que a afetividade humana, por excmplo, muito teria a dizer.

Por outro lado, acreditamos que não é porque se pretende transformar o perfil tradicional do ensino que se deva, também, modificar as finalidades perseguidas, de "desenvolvimento das potencialidades" do aluno e de sua capacidade de pensar. Apenas, os termos destas finalidades deveriam ser reconccituados.

A começar com potencialidades, elas não são inatas, mas lentamente adquiridas. No domínio intelectual e sob a perspectiva piagetiana, constituem-se na própria inteligência como definicla atrás: conjunto de estruluras cm um dado nivel de desenvolvimento. Tais estruturas podem, por assim dizer,

(3) A noção de compelência é lomada por PIACET dos estudos de WADDINGTON sobre embriogênese. Enquanto caso particular da função assimiladora, significa que o individuo mostra-se sensivel a certos estimulos somente se dispuser de esquemas se assimilação apropriados. 
ser vistas como "trabalho virtual", funcionando como condutas latentes a serem atualizadas, tornadas reais.

Desenvolver as potencialidades significa, não impor às estruturas um ritmo e direção "de fora", mas dar condições para que sejam atualizadas. Para tanto, são necessárias pressões ambientais, dạdo que toda ação transformadora, não se fazendo no vazio, requer um objeto de transformação, mesmo que este objeto seja o próprio sujeito, com suas resistências à assimilação.

Pretender, enfim, desenvolver as potencialidades do aprendiz e sua capacidade de agir mentalmente é o mesmo que favorecer o desenvolvimento, livre e espontâneo, da operatividade. E, neste caso, sem perder a especificidade, o ensino formal poderia aproximar-se da "aprendizagem natural": esta não dependente da transmissão escolar, do conteúdo acadêmico e da relação pedagógica desenvolvida nos limites estreitos da sala de aula.

\section{REFERÊNCIAS BIBLIOGRÁFICAS}

AEBLI, H. (1978) Didática Psicológica. 3 cd., São Paulo, Nacional.

BARRETO, E. S. de SÁ. (1981) Professores de periferia: soluções simples para problemas complexos. In: PATTO, M. H. S. (Org.). Introdução à Psicologia Escolar. São Paulo, Queiroz.

BOHOSLAVSKY, R. H. A psicopatologia do vínculo professor-aluno: o professor como agente socializante. In: PATTO, M. H. S. Org.). Op. Cit..

CHAGAS, V. (1978) Educação Brasileira: o ensino de $1^{\circ}$ e $2^{\circ}$ gुr us. São Paulo, Saraiva.

COLL, C. (1978) As contribuições da psicologia para a educação: teoria genética e aprendizagem escolar. In: LEITE, L. B. (Org.) Piagel e a Escola de Gencbra. São Paulo, Cortez.

FURTH, H. G. (1972) Piaget na Sala de Aula. Rio de Janeiro, Forense.

FURTII, H. G. (1974) Piaget e o Conhecimento. Rio de Janciro, Forense Universitária.

GUINSBURG, G. K. (1978) Dificuldades de aprendizagem nas áreas de ciências e algumas de suas origens. Simpósio sobre Ensino de Biologia, Física, Matemática e Química ( $1^{\circ}$ e $2^{\circ}$ Graus) no Estado de São Paulo. Anais. São Paulo, (11): 116-171 
PI^GET, J. (1973 a) Problemas de Psicologia Genélica. R. de Janeiro, Forensc.

(1973 b) Biologia e Conhecimento. Petrópolis, Vozes.

(1975) A Formação do Símbolo na Criança. Rio de Janeiro, Zahar

(1976 a) A Equilibração das Estruturas Cognitivas: problema central do desenvolvimento. Rio de Janeiro, Zahar.

(1976 b) Psicologia e Pedagogia. 4 ed., Rio de janciro, Forense Universitária.

SÃO PAULO, SECRETARIA DA EDUCAÇÃO. (1973) Documentos básicos para a implantação do Ensino de $1^{\circ}$ e $2^{\circ}$ Graus. Dirctrizes e Bases da Educação Nacional.

SÑO PAULO, SECRETARIA DA EDUCAÇÃO. (1975) Guias Curriculares para as Matérias do Núclco Comum do Ensino de $1^{\circ}$ Grau. CERH IUPE.

\section{TEACHING PRACIICE GROUNDWORKS: TOWARDS AN ACTIVE PEDAGOGY}

\section{ABSTRACT}

The paper intends to show how the question of the teaching practice groundworks is a top priority in a discussion about the teacher's failures, incoherences and dissatisfactions in his daily work. Such groundworks are considered as the starting point for an analysis of the present teaching. Misunderstandings and ambiguilies of the teaching practice and the persistence of characteristics of traditional pedagogy are pointed out, together with its assumptions and implications for the sludents' development and learning as well. At the end, Piagetian psychological and epistemological principles on which an active pedagogy may be founded are presented along with some cues for its effecliveness in practice, intending to serve the educational aim of "development of the learner's potentialities" according to new basis.

KEY WORDS: active pedagogy, traditional teaching, teaching practice groundworks, principles of Piagetian theory.

Palavra chave: pedagogia ativa, ensino tradicional, tundamentos da prática docente, princípios da tcoria piageliana. 